broth cultures of pneumococci and " mouse pathogenic green streptococci" were used because in animal experiments it had been found that they were more effective in producing immunity than saline suspensions, and experiments with human volunteers showed that the use of serum broth did not result in unduly severe reactions.

\section{Source of CASES}

I obtained the co-operation of a number of Leeds general practitioners, who sent cases suffering from unusually frequent and severe attacks of coryza. A clinical history was obtained from each patient, and an examination of his upper respiratory flora was made by the methods described previously (Hoyle, 1932). An autogenous vaccine was prepared as set oùt above, and a course of three injections given at weekly intervals$0.25 \mathrm{c} . \mathrm{cm}$. for the first and second doses, and a third and final dose of $1 \mathrm{c} . \mathrm{cm}$. Six months later a record of progress was obtained, and any patient desiring a further course of vaccine was examined again and a fresh vaccine prepared and administered.

\section{Bacteriology and Results}

As was expected, these individuals showed unusually large numbers of pathogenic bacteria in the upper respiratory tract. Out of ninety-four cases examined, in only one case were no pathogenic bacteria detected. Pneumococci were isolated in 59 per cent. of the cases, $B$. influenzae in 52 per cent., " mouse pathogenic green streptococci " in 72 per cent., haemolytic streptococci in 32 per cent., and Friedländer's bacillus in 11 per cent.

It was only possible to obtain satisfactory records in sixty-seven cases, and the results in these cases were as follows: twenty-eight cases derived no benefit whatever; in twenty-three cases the incidence of acute coryza was not affected, but the severity of the attacks was reduced; sixteen cases showed a definite reduction in both the frequency and the severity of the attacks. These results indicate that autogenous anti-catarrhal vaccines, like stock vaccines, do not appreciably affect the incidence of attacks of acute coryza, and although some cases showed a reduction in the severity of attacks, this was not, in my opinion, sufficient to justify any very extensive use of such vaccines. It has been suggested that the failure of anti-catarrhal vaccines is due to the causal agent of coryza being absent from the vaccine; but as the immunity conferred by an attack of coryza is negligible, there appears to be no reason for supposing that any greater degree of immunity is to be expected from vaccine therapy, and it is probable that a reduction in severity of the attacks is the most that can be expected.

\section{SUMMARY}

Sixty-seven individuals suffering from very frequent and severe attacks of coryza have been treated by autogenous vaccine therapy. The results show that the vaccine exerts no influence on the incidence of attacks. The suggestion has been made by previous workers that, while stock anti-catarrhal vaccines have no effect on the incidence of acute coryza, they tend to diminish the frequency of severe complications such as pneumonia, and this suggestion has been supported by a small number of cases treated by autogenous vaccines.

I should like to express my indebtedness to a number of Leeds general practitioners who have assisted me in this investigation, to the Medical Research Council from whom I am in receipt of grants, and to Professor J. W. McLeod for some helpful criticism.

\section{Bibliography}

Ferguson, F. R., Davey, A. F. C., and Topley, W. W. C.: Journ. of Hyg., xxvi, 98.

Hoyle, L.:" Journ. Path. and Bact., xxxv, 817.

Jordan, E. O., and Sharp, W. B.: Journ. Infect. Dis., xxviii, 357.

Von Sholly, A. I., and Park, W. H.: Journ. Immunol., vi, 103.

webster, L. T., and Clow, A. D.: Journ. Exp. Med., lv, 445.

\section{ACETYLCHOLINE IN THE TREATMENT OF EPILEPSY}

BY

F. L. MCLAUGHLIN, M.D., D.P.M.

ASSISTANT MEDICAL OFFICER, COLNEY HATCH ; CLINICAL ASSISTANT, DEPARTMENT OF PSYCHOLOGICAL MEDICINE, UNIVERSITY COLLEGE HOSPITAL

Since Hughlings Jackson, ${ }^{1}$ in 1870 , pointed out the possibility of the epileptic seizure being determined by contraction of the cerebral arteries, the role of "vascular spasm" in this disorder has been a subject of clinical and experimental interest. Vascular spasm is a mechanism now accepted by many clinicians as explaining a number of cases of transitory aphasias, hemianopias, and migraine. The sudden blanching of the extremities as a result of vaso-constriction is well illustrated in Raynaud's disease. The association of Raynaud's disease with cerebral vascular disturbances has been recorded by Norman, ${ }^{2}$ and by Carp. ${ }^{3}$ Russell ${ }^{4}$ has noted the similarity between the stages of the epileptic convulsion and the symptoms accompanying heart-block in Stokes-Adams's disease. Many observations of the exposed cortex during epileptic attacks have been made. Foerster ${ }^{5}$ describes the sequence of events repeatedly seen by him on the operating table. Sudden pallor of the cortex and arrest of cerebral pulsation is immediately followed by extreme hyperaemia, venous engorgement, and bulging of the brain. Horsley, ${ }^{6}$ Leriche, $^{7}$ and Kennedy and Hartwell ${ }^{8}$ have observed practically similar changes. Corroborative evidence is to be found in the observations of the fundus oculi during an attack. Jackson ${ }^{9}$ long ago noticed that the fundus was pale before a seizure; during the convulsion the veins became large and dark. Experimental evidence has recently been brought forward to show that the cerebral vessels contract after stimulation of the cervical sympathetic and dilate in response to vagus stimulation (Schilf, ${ }^{10}$ Forbes and Wolffil ${ }^{11}$. The effect of these observations has been to bring again to the foreground the hypothesis that fits are precipitated by cerebral vaso-constriction. But although it is now generally acknowledged that the cerebral arteries are under vasomotor control, a causal relationship between cerebral vaso-constriction and the epileptic attack is by no means accepted (Notkin et al., ${ }^{12}$ Wilson $^{13}$ ). On the assumption that seizures are due to vaso-constriction of the cerebral arteries various operations on the cervical sympathetic chain have been performed in epileptic patients (Alexander, ${ }^{14}$ Bojovitch, ${ }^{15}$ Tinel, ${ }^{16}$ Zavialoff, ${ }^{17}$ Lauwers $\left.{ }^{18}\right)$. The results of cervical sympathectomy have on the whole been disappointing. Favourable results in certain subjects are reported recently by Lauwers ${ }^{10}$ following the removal of the carotid body.

Attempts to influence epileptic attacks by the administration of vaso-dilator substances have been made. Popea and Eustatziou ${ }^{20}$ in 1927 recorded beneficial results following the inhalation of amyl nitrite at the onset of attacks. In 1929 Villaret and Justin-Besançon ${ }^{21}$ demonstrated the therapeutic value of injections of acetylcholine in Raynaud's disease, arteritis, and similar complaints. The beneficial effects of acetylcholine in Raynaud's disease appeared to lend support to the vaso-constriction theory of epilepsy. In: 1931 Etienne E $^{22}$ and his co-workers at Nancy investigated the action of this substance in a group of seven epileptics. In two cases a notable reduction in the fit incidence was recorded. Later, de Gennes ${ }^{23}$ reported that injections of acetylcholine arrested the seizures in two cases of status epilept:cus. Similar results were described by Pagniez, Plichet, and Decourt. ${ }^{24}$ Dino Bolsi $^{25}$ in 1932 reported a dramatic reduction in the number of seizures in five of his eight cases. In some of the group investigated the beneficial effect persisted for several days after the injections of acetylcholine. 
On the other hand, Dejean and Hughes ${ }^{26}$ in four cases treated over a fourteen-day period did not obtain any favourable results.

\section{EXPERIMENTAL}

The therapeutic effect of acetylcholine and pacyl was investigated in fourteen epileptics at Colney Hatch Mental Hospital. The cases selected were subject to frequent major convulsive attacks, which were unassociated with ascertainable organic disorder in the nervous system or elsewhere. The age of onset of the disorder and the age at the time of the investigation are shown in the table. Either some degree of congenital mental defect or progressive mental deterioration was present in all members of the group. During the experiment no change was made in the diet, usual medication, or regimen of the subjects. The type and frequency of all convulsions, aurae, and equivalents were recorded for stated periods before, during, and after treatment.

Table showing age of onset of the disorder, present age, and the number of seizures occurring. during the fourteen-day periods before, during, and afler treatment with acetylcholine bromide injections (0.1 to 0.3 gram) and pacyl (two tablets three times daily).

\begin{tabular}{|c|c|c|c|c|c|c|c|}
\hline 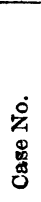 & 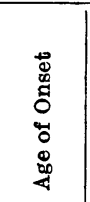 & 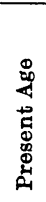 & 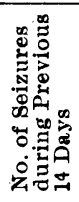 & 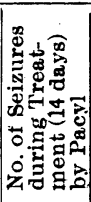 & 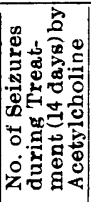 & 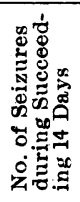 & Results \\
\hline 1 & 14 & 22 & 23 & 32 & 20 & 19 & Unchanged \\
\hline 2 & 7 & 31 & 34 & 29 & 30 & 41 & Unchanged \\
\hline 3 & 16 & 26 & 5 & 4 & 1 & 6 & Improved \\
\hline 4 & 7 & 23 & 5 & 4 & 3 & 4 & Unchanged \\
\hline 5 & Infant & 30 & 7 & 8 & 3 & 1 & Improved \\
\hline 6 & Infant & 39 & 4 & 4 & 4 & 3 & Unchanged \\
\hline 7 & 11 & 23 & 37 & 66 & *- & - & Unimproved \\
\hline 8 & 3 & 24 & 5 & $\begin{array}{c}\text { Acetyl- } \\
\text { choline } \\
1\end{array}$ & $\underset{5}{\text { Pacyl }}$ & 5 & Improved \\
\hline 9 & 3 & 29 & 3 & 1 & 2 & 4 & Improved \\
\hline 10 & Infant & 33 & 2 & 0 & 2 & 1 & Improved \\
\hline 11 & Infant & 21 & 5 & 4 & 5 & 5 & Uncbanged \\
\hline 12 & Infant & 18 & 2 & 12 & 12 & 4 & Unimproved \\
\hline 13 & Infant & 14 & 19 & 18 & 18 & 12 & Unchanged \\
\hline 14 & 12 & 20 & 9 & 7 & 9 & 8 & Unchanged \\
\hline
\end{tabular}

* Treatment stupped on account of increase in number and severity of seizures.

Acetylcholine bromide (B.D.H.) was administered by subcutaneous injection each morning for fourteen days. The initial dose given was 0.1 gram, followed by a daily dose of 0.15 gram. After seven days the dose was increased to 0.3 gram. Pacyl is a derivative of choline and has the advantage of oral administration. Its action as a parasympathetic stimulant is said to be more constant than that of acetylcholine. Two pacyl tablets were given three times daily for fourteen days. Half the cases were first given a course of pacyl tablets, followed by a course of acetylcholine injections. In the other seven subjects this procedure was reversed.

\section{Discussion}

The influence of pacyl tablets and acetylcholine injections is shown in the table. No beneficial effect was observed during pacyl administration. During acetylcholine treatment it will be noted that in five cases a reduction of the number of seizures occurred. There was no association between the decrease in the number of convulsions and the increased dosage $(0.3$ gram $)$ given during the second week. In two cases diminution in the number of seizures was accompanied by an increase in psychic equivalents. No change in the type or severity of the seizures was observed in the other three cases, classified as improved. One of these (No. 8) became brighter and more energetic, and this mental improvement was maintained for some weeks, although the number of fits again increased after treatment. There was no mental change noted in the other two patients, who showed decrease of fits during the injections. Case No. 5, where a decrease in the number of seizures occurred during the fourteen-day period succeeding acetylcholine administration, was confined to bed at this time. With regard to Case No. 7, a great increase in the number and severity of attacks coincided with the end of the pacyl treatment. An attempt to arrest the rapidly repeated seizures by two 0.4 gram doses of acetylcholine failed, and this form of treatment was in consequence stopped. The results obtained in the seven cases classified as unchanged do not call for individual discussion.

\section{COMmEnT}

The question arises whether the beneficial effect occurring in a few cases of the group during acetylcholine therapy may not be dependent on some factor other than the action of this substance. It is well known that periodic fluctuations in the incidence of seizures occur in many epileptics. An investigation of the incidence of fits occurring in these cases during the previous three months, when the subjects were under the same conditions in all respects except for acetylcholine treatment, did not disclose any fourteen-day periods comparable with those which have been held to justify the use of the word " improved" in the table. While, therefore, there was no dramatic reduction in the incidence of seizures, it would seem that a small proportion of the group are less susceptible to attacks when under the influence of acetylcholine.

The results obtained from the administration of the choline derivative, pacyl, were discouraging. On the whole, it may be said that the results which followed the use of these arterial antispasmodic substances do not lend definite support to the hypothesis that cerebral vasoconstriction is by itself the precipitating factor of the epileptic attack. It must, however, be admitted that the action of the drugs may not be the same in the case of the cerebral circulation as in the peripheral vessels of the body.

The writer is indebted to Dr. F. Golla, who suggested this investigation, and to Dr. J. Brander, for his help and criticism.

\section{REFERENCES}

1 Jackson, J. Hughlings: Trans. St. Andrews Med. Grad. Assoc., 1870, iii; reprinted in Selected Writings of John Hughlings Jacksom, 1931, i, 8

2 Norman, H. J.: Journ. Ment. Sci., 1916, 1xii, 730.

3 Carp, I. A Ar.h. of Surg., 1931, xxii, 353.
Russell, A. E.: Cited by Kinnier Wilson, loc. cit.

"Foerster, C.: Deut. Zeit. f. Neruewheilk., 1926, xciv, 15.

"Horsley, Victor: British Medical Journal, 1892, i, 693

Leriche, R.: Presse Méd., 1920, xxviii, 645

Kennedy and Hartwell: 'Arch. Neurol. and Psychtat., 1923, ix, 571.

- Jackson, J. Hughlings: Med. Times and Gazette, 1863, ii, 359.

o Schilf, E.: Das Autonome Nervensystem, 1926, Leipzig, George Thième, p. 104

${ }^{11}$ Forbes, H. S., and Wolff, H. G.: Arch. Neurol. and Psychiat., 1928, xix, 1057 .

12 Notkin, J., Coombs, H. C., and Pike, F. H.: Amer. Journ. Psychiat., 1932, xi, 679.

13 Wilson, Kinnier: Modern Problems in Neurology, 1928.

14 Alexander, W.: The Treatment of Epilepsy, 1889

15 Bojovitch, V.: Rev. de Chir., 1925, lxiii, 608

${ }_{16}$ Tinel, M. J.: Rev. Neurol., 1925, xli, 613.

17 Zavialoff, I.: Vestnif. Khir., 1927, xi, 131

${ }^{18}$ Lauwers, E.: Journ. de Chir., 1931, xxxvii, 686

19 Idem: Rev. Neurol., 1932, xxxix, i, 1377

20 Popea, A., and Eustatziou, G.: Presse Méd., 1927, xxxv, 643.

21 Villaret, $\mathrm{M}$., and Justin-Besancon, L.: Lancet, 1929, i, 493 : Leçons du Dimanche, 2 série, 1930.

${ }^{22}$ Etienne, G., Louyot, P., Mle Cullerie, and Simonin, J.: Rev. Méd. de l'Est., 1931, lix, 166.

${ }^{23}$ De Gennes, L.: Soc. Méd. des Hôp. de Paris, 1932, xlviii, 394.

24 Pagniez, Plichet, and Decourt: Ibid., 1932, xlviii, 424

${ }^{25}$ Bolsi, D. : Rev. Neurol., 1932, xxxix, i, 1321.

26 Dejean, C., and Hugues, P.: Arch. Soc. des Sci. Méd. de Montpellier, 1932, xiii, 212. 